Arq. Bras. Med. Vet. Zootec., v.64, n.5, p.1109-1117, 2012

\title{
Imunoistoquímica de útero e cérvice de cadelas com diagnóstico de piometra
}

[Immunohistochemical of the cervix and uterus of bitches diagnosed with pyometra]

R. Volpato, I. Martin, R.S. Ramos, M.H. Tsunemi, R. Laufer-Amorin, M.D. Lopes

Faculdade de Medicina Veterinária e Zootecnia (UNESP-Botucatu)

\begin{abstract}
RESUMO
Analisou-se a piometra de 31 cadelas, de raças e idades variadas, sendo 25 cadelas com piometra de cérvice aberta e seis de cérvice fechada. Após ovariossalpingo-histerectomia, foram coletados fragmentos da cérvice e do útero para a avaliação imunoistoquímica. Foram analisados os receptores de estrógenos $\alpha$ e $\beta$, progesterona e colágenos I e III. Foram realizadas imunomarcações em diferentes regiões da cérvice, como o epitélio glandular, o epitélio luminal e o estroma glandular, assim como em diferentes regiões do útero, como o epitélio glandular e o estroma glandular. As imunomarcações de colágenos I e III foram realizadas nas regiões glandular e muscular da cérvice e do útero. Concentrações de receptores de progesterona foram maiores em cadelas com piometra fechada.
\end{abstract}

Palavras-chave: cadela, imunoistoquímica, piometra

\begin{abstract}
The pyometra in 31 bitches of different breeds and ages, 25 with pyometra cervix open and 6 closed cervix was analyzed. After the ovariohysterectomy procedure, samples were collected from the cervix and uterus to evaluate immunohistochemistry. For immunohistochemical evaluation estrogen receptors $\alpha$ and $\beta$, progesterone and collagen I and III were analyzed. Immunostainings were performed in different regions of the cervix such as glandular epithelium, luminal epithelium and glandular stroma, as well as in different regions of the uterus, such as glandular epithelium and glandular stroma. The immunostainings for collagen I and III were performed in muscular and glandular regions of the cervix and uterus. The concentration the progesterone receptors were elevated in bitches from the closed pyometra.
\end{abstract}

Keywords: bitches, immunohistochemistry, pyometra

\section{INTRODUÇÃO}

A piometra é caracterizada pela inflamação do útero com acúmulo de exsudato, a qual ocorre na fase lútea do ciclo estral (Coggan et al., 2004; Smith, 2006). No diestro ocorre uma hipertrofia/hiperplasia do endométrio, estimulada pela progesterona $\mathrm{e}$, subsequentemente, uma invasão bacteriana (Weiss et al., 2004). Trata-se de uma das enfermidades mais comuns do trato genital das fêmeas caninas (Pretzer, 2008; Goericke-Pesch et al., 2010). Segundo Hagman et al. (2011), os fatores de risco podem variar entre as raças, e a gestação é considerada um fator protetor.

\begin{abstract}
A patogênese da piometra canina não é completamente esclarecida, mesmo após décadas de estudo. O conceito de Síndrome Hiperplásica Endometrial Cística /Piometra, introduzido por Dow $(1957 ;$ 1958), sugere que mudanças hormonais provocam a hiperplasia endometrial cística (HEC) e torna o útero mais susceptível à infecção secundária. Mais recentemente, De Bossechere et al. (2001) sugeriram que, devido às diferenças clínicas e histopatológicas, a HEC e a piometra devem ser classificadas separadamente. É comum a piometra ser definida como um complexo endometrite/HEC/piometra (Arora et al., 2006).
\end{abstract}

Recebido em 7 de julho de 2011

Aceito em 20 de julho de 2012

E-mail: rodrigo.volpato@hotmail.com 
Há um consenso de que as lesões observadas na piometra são resultado de uma interação hormonal e participação bacteriana. Apesar dos vários estudos sobre o tema, clinicamente a síndrome piometra ainda representa um desafio para a maioria dos profissionais, sendo difícil estabelecer um prognóstico preciso (de Cock et al., 1997; Ferreira e Lopes, 2000; Weiss et al., 2004; Martins, 2007).

A piometra pode ser de forma aberta ou fechada, caracterizada pela presença ou ausência de corrimento vaginal, respectivamente. A cérvice é considerada uma barreira física prevenindo a infecção ascendente pela secreção de muco e constricção; a abertura ou o fechamento da cérvice são ciclo dependentes, e os mecanismos de dilatação cervical nas cadelas não são totalmente esclarecidos (Chatdarong et al., 2008).

A piometra tem sido associada a repetidas e prolongadas respostas ao estrógeno durante o estro, seguida por longos intervalos de dominância da progesterona (Smith, 2006; Pretzer, 2008). O endométrio sob o estímulo da progesterona se hipertrofia devido a um aumento no número e no tamanho de suas glândulas, que aumentam suas atividades secretoras, e um fluido estéril pode se acumular no lúmen do útero. Essas respostas às ações hormonais podem ser mais exacerbadas com o uso de progestágeno exógeno (de Bosschere et al., 2001; Ragni, 2005; Pretzer, 2008).

Sob a influência estrogênica, a cérvice se abre, o que permite a entrada de bactérias (Oliveira, 2007; Oliveira et al., 2008). A patência da cérvice é regulada pela musculatura lisa, pelo tecido fibroso e pela elastina. A remodelação da matriz extracelular tem um papel importante na dilatação cervical pela degradação do colágeno. Em trabalho realizado por Chatdarong et al. (2010), foi postulado que o útero de cadelas cíclicas tem maior proporção de colágeno comparado à proporção de musculatura lisa, levando à diminuição da resistência à tração e causando, assim, o relaxamento da cérvice. Resultado semelhante foi observado nas cadelas com piometra de cérvice aberta, sugerindo que a abertura é associada a um aumento na proporção de colágenos frente a fibras musculares (Chatdarong et al., 2010).
Anticorpos monoclonais para receptores de estrógenos humanos foram utilizados para detectar a presença de receptores de estrógeno no útero de cadelas normais e com HEC. Como resultado, obteve-se uma diferença importante, um maior número de receptores em cadelas com HEC, já que os estrógenos são os responsáveis pela proliferação das glândulas do endométrio uterino (de Bosschere et al., 2002a; de Bosschere et al., 2003, Ververidis et al., 2004).

De Bosschere et al. (2002b) avaliaram, por ensaio imunoistoquímico, a expressão de receptores de estrógeno (REs) e receptores de progesterona (RP4) no útero de cadelas normais, com piometra e com HEC. As contagens de RE e RP4 foram mais elevadas nos animais com HEC, sendo que a menor contagem foi verificada em cadelas com piometra. As diferenças na expressão de receptores sugerem fatores distintos na patogênese de ambas as entidades. Assim, pode-se pensar que a piometra é desencadeada por uma cascata de eventos iniciada pela infecção bacteriana.

Em consequência da expressão significativamente aumentada do RE em cadelas com HEC, o endométrio permanece receptivo ao hormônio mesmo com níveis baixos de estrógeno circulante. Isto pode esclarecer a contínua proliferação das glândulas endometriais durante o estágio de forte influência da progesterona. A ação prolongada simultânea do estrógeno e da progesterona poderia explicar as mudanças na proliferação cística que são características da piometra (de Cock et al., 1997).

\section{MATERIAL E MÉTODOS}

A presente pesquisa atendeu aos requisitos impostos pela Comissão de Ética no uso de animais, de acordo com os princípios éticos na experimentação animal da Faculdade de Medicina Veterinária e Zootecnia da UNESP, campus Botucatu, protocolo número 26/2009 CEEA.

Foram utilizadas 31 cadelas com diagnóstico de piometra atendidas na área de reprodução de pequenos animais. Do total de cadelas, 25 apresentavam secreção vaginal purulenta, mucopurulenta ou sanguinolenta, e seis piometra de cérvice fechada. Após o procedimento de ovariossalpingo-histerectomia (OSH), foram 
coletados fragmentos da cérvice e do útero para a avaliação imunoistoquímica.

Os fragmentos uterinos e cervicais foram fixados em formol tamponado $10 \%$ durante 24 horas e, depois, mantidos em álcool $70 \%$ até o momento de inclusão em parafina. Após a inclusão, cortes de $3 \mu \mathrm{m}$ foram obtidos, montados em lâminas e corados inicialmente em HE para avaliar a qualidade do material. Posteriormente novos cortes de $3 \mu \mathrm{m}$ foram realizados e colocados em lâminas com extremidade fosca, previamente tratadas com Poly-L-lysina (Poly-L-lisine ${ }^{\circ}$ Sigma Chemical Co., USA).

Para a desparafinização do material emblocado, as lâminas foram mantidas em estufa a $55^{\circ} \mathrm{C}$ por 24 horas, após o que foram colocadas em cuba de vidro com xilol à temperatura ambiente por 30 minutos e, a seguir, em nova solução de xilol por 20 minutos. As lâminas foram transferidas para a hidratação em banhos de álcool, permanecendo por três minutos em cada cuba (álcool absoluto I, II, III, álcool 95\% e 85\%). Posteriormente, as lâminas foram submetidas a 10 passagens de água destilada. A partir desta etapa, o tratamento se difere para cada antígeno pesquisado.

Para a detecção de RE $\alpha$, realizou-se a recuperação antigênica em solução de citrato de sódio $10 \mathrm{mM}(1000 \mathrm{~mL}$ de água destilada e $2,1 \mathrm{~g}$ de ácido cítrico mono-hidratado, com $\mathrm{pH}$ corrigido para 6,0 com ácido clorídrico) com incubação em panela de pressão tipo pascal (Dako, USA). A etapa seguinte foi o bloqueio da peroxidase endógena em solução de água oxigenada $8 \%$ por 20 minutos, 10 lavagens em água destilada, bloqueio com leite em pó Molico ${ }^{\circledR} 3 \mathrm{~g} / 100 \mathrm{~mL}$ por 60 minutos, seguidas de 10 passagens em água destilada e lavagens em solução tampão Tris-pH 7,4 (Trizma Base®Sigma Chemical Co, USA). Realizou-se a incubação com o anticorpo primário, na diluição de 1:50 (anticorpo Monoclonal Mouse AntiHuman Estrogen Receptor $\alpha$ clone 1D5 - Dako CA, USA, Cód M7047), em câmara úmida, durante $18 \mathrm{~h}$, à temperatura de $4^{\circ} \mathrm{C}$.

Para a detecção de RE $\beta$, realizou-se a recuperação antigênica em solução de citrato de sódio $10 \mathrm{mM}$ com incubação em micro-ondas, potência máxima $-750 \mathrm{~W}$, durante 15 minutos. A etapa seguinte foi o bloqueio da peroxidase endógena em solução de água oxigenada $8 \%$ por
20 minutos, 10 lavagens em água destilada, bloqueio com leite Molico ${ }^{\circledR} 3 \mathrm{~g} / 100 \mathrm{~mL}$ por 60 minutos, seguidas de 10 passagens em água destilada e lavagens em solução tampão Tris-pH 7,4. Realizou-se a incubação com o anticorpo primário, na diluição de 1:100 (anticorpo Monoclonal Mouse Anti-Human Estrogen $\beta$ clone PPG5/10, Dako, USA, Cód. M7292), em câmara úmida, durante $18 \mathrm{~h}$, à temperatura de $4^{\circ} \mathrm{C}$.

Para a detecção de RP4, realizou-se a recuperação antigênica em solução de citrato de sódio 10mM com incubação em panela de pressão tipo pascal (Dako, USA). A etapa seguinte foi o bloqueio da peroxidase endógena em solução de água oxigenada $8 \%$ por 20 minutos, 10 lavagens em água destilada, bloqueio com leite Molico ${ }^{\circledR} 3 \mathrm{~g} / 100 \mathrm{~mL}$ por 60 minutos, seguidas de 10 passagens em água destilada e lavagens em solução tampão Tris-pH 7,4. Realizou-se a incubação com o anticorpo primário, na diluição de 1:50 (anticorpo monoclonal cat. No 1546, Immunotech, France), em câmara úmida, durante $18 \mathrm{~h}$, à temperatura de $4^{\circ} \mathrm{C}$.

Para a detecção de colágenos I e III, realizou-se recuperação antigênica em pepsina 1\%, pH 1,8 (Pepsina 1:1000 NF- Nuclear, SP, Brasil), com incubação em estufa a $60^{\circ} \mathrm{C}$ por 10 minutos e, em seguida, a $37^{\circ} \mathrm{C}$ por 20 minutos. A etapa seguinte foi o bloqueio da peroxidase endógena em solução de água oxigenada $8 \%$ por 20 minutos, 10 lavagens em água destilada, bloqueio com leite Molico ${ }^{\circledR} 3 \mathrm{~g} / 100 \mathrm{~mL}$ por 60 minutos, seguidas de 10 passagens em água destilada e lavagens em solução tampão Tris-pH 7,4. Realizou-se a incubação com o anticorpo primário, na diluição de 1:2000, para colágenos I e III (respectivamente, Rabbit anti bonvine col I IgA Novotec. Ref. 20121; Rabbit anti bovine col III IgA Novotec, Ref. 2930), em câmara úmida, durante $18 \mathrm{~h}$, à temperatura de $4^{\circ} \mathrm{C}$.

As próximas etapas foram semelhantes para todos os antígenos. Após 18 horas de incubação com o anticorpo primário em câmara úmida a $4^{\circ} \mathrm{C}$, o material foi, então, submetido a banhos de TRIS e, posteriormente, incubado com o anticorpo secundário Advance (Advance, Dako, USA) por 30 minutos cada etapa, segundo instruções do fabricante. Realizou-se nova lavagem com solução tampão TRIS - pH 7,4 e 
revelação com o cromógeno DAB (3,3'-diaminobenzidina - Liquid DAB Cromogen ${ }^{\circledR}$ - Dako, USA), durante cinco minutos, e novamente lavagem com solução tampão TRIS - pH 7,4.

As lâminas foram contracoradas com hematoxilina de Mayer por 30 segundos, e a coloração interrompida com lavagem em água corrente por 10 minutos e cinco passagens em água destilada. Procedeu-se, então, à desidratação do material com banhos de álcool. As lâminas permaneceram três minutos em cada cuba (álcool 85\%, 95\%, álcool absoluto I, II, III, xilol I e II) e, por fim, foram montadas com lamínulas utilizando-se resina sintética Permount (Fisher Scientific - cód. UN1294e).

Como controle negativo, em outro corte da cérvice e do endométrio, foi empregada a substituição do anticorpo primário pela imunoglobulina deste, ou seja, foi utilizada imunoglobulina de camundongo quando se tratava de anticorpos monoclonais (N-Universal Negative Control Mouse - DakoCytomation, CA, USA, Cód N1698) e frações de imunoglobulinas séricas de coelho para o anticorpo policlonal (N-Universal Negative Control Rabbit - DakoCytomation - CA, USA. Cód N1699).

Depois de todas as lâminas confeccionadas e identificadas, realizou-se a leitura.

Para os RE $\alpha$, RE $\beta$ e RP4, os tecidos avaliados na cérvice foram o epitélio luminal, o epitélio glandular e o estroma. No útero, os tecidos avaliados foram o epitélio glandular e o estroma. Todas as avaliações para o útero e a cérvice foram realizadas nestes tecidos. Para avaliar a imunomarcação, foram utilizados dois métodos; no primeiro, em cada um desses tecidos, foram contados 300 núcleos, sendo considerados positivos aqueles corados em marrom, e negativos aqueles corados em azul; no segundo método, a intensidade das marcações foi avaliada, de forma subjetiva, em fraca, moderada e forte. As avaliações foram realizadas em um microscópio de luz com aumento de 400 vezes.

Para os colágenos I e III, a mesma forma de avaliação foi empregada para o útero e a cérvice.
Dois métodos foram utilizados para avaliar a imunomarcação. No primeiro, dez campos aleatórios, nos tecidos muscular e estroma, eram observados em microscópio de luz com aumento de 100 vezes. Cada campo recebia escore de 1 (menos de $25 \%$ do campo corado de marrom), 2 (26\% a $50 \%), 3(51 \%$ a $75 \%)$ ou 4 (acima de $75 \%$ ). A média dos campos foi realizada calculando-se o escore definitivo daquela lâmina. No segundo método, a intensidade foi classificada, de forma subjetiva, como fraca (menos de $20 \%$ das fibras coradas), moderada (26\% a $75 \%$ ) e forte (acima de $76 \%$ ).

Para comparar os resultados entre os grupos de piometra aberta e piometra fechada, utilizou-se o teste não paramétrico de Mann-Whitnney. Os resultados foram avaliados considerando-se $\mathrm{P}<$ 0,05. A frequência das intensidades dos núcleos positivos (fraco, moderado e forte) entre as regiões teciduais estudadas foi comparada pelos testes qui-quadrado e exato de Fisher. Nos casos em que houve associação significativa, realizouse a partição da tabela qui-quadrado, em que se comparam as frequências entre os locais estudados.

\section{RESULTADOS E DISCUSSÃO}

A avaliação imunoistoquímica empregada neste trabalho foi capaz de marcar os núcleos das células que possuíam receptores. Por ser uma técnica semiquantitativa, a presença e a intensidade da marcação refletem, respectivamente, a positividade da célula e a concentração destes receptores. As duas variáveis podem ser utilizadas. Em alguns trabalhos, os autores avaliaram o número de núcleos positivos e sua intensidade (Boos et al., 1996; Martin et al., 2008; Martin, 2009); em outros, os pesquisadores avaliaram apenas a intensidade da marcação (Robinson et al., 2001), ou, ainda, apenas a identificação foi realizada (Breeveld-Dwarkasing et al., 2002). Neste estudo, optou-se pela realização das duas avaliações.

Neste experimento, foram realizados exames imunoistoquímicos para a identificação e a quantificação de colágenos I e III (Fig.1) e dos RE $\alpha$ e RE $\beta$, RP4 (Fig.2) em diferentes regiões do útero e da cérvice. 


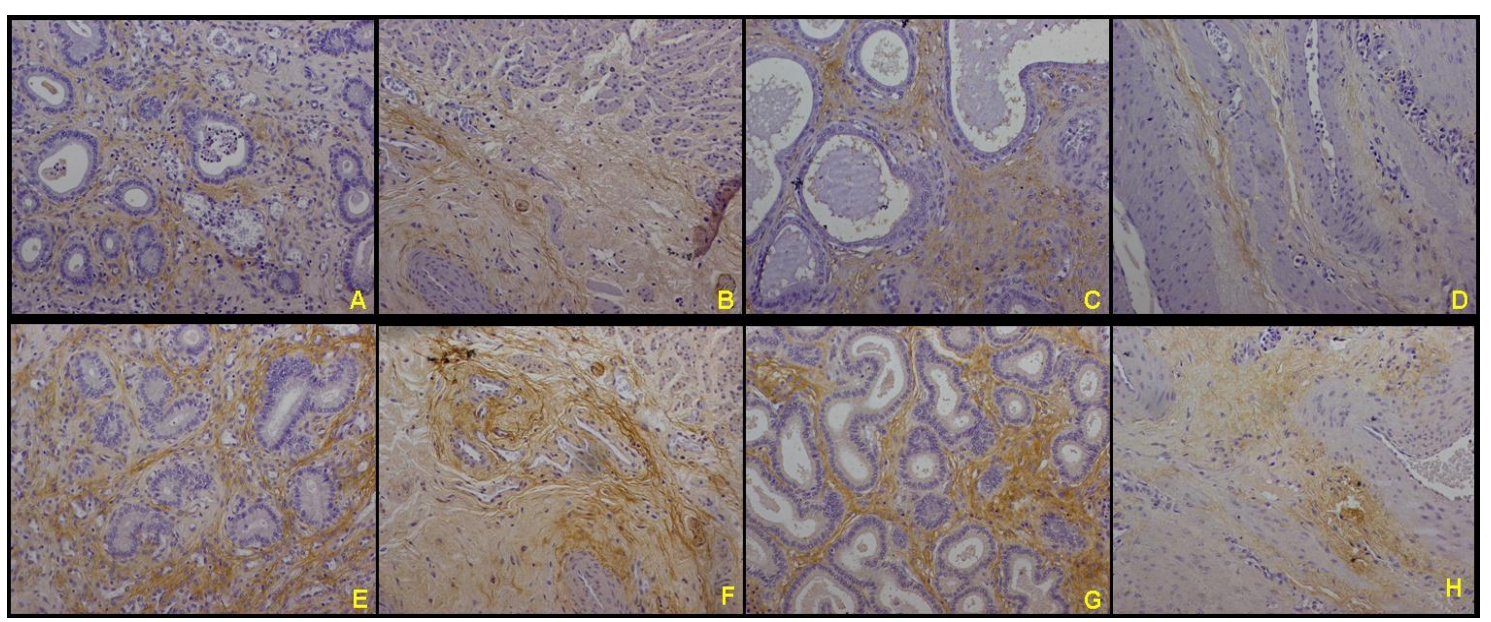

Figura 1. Imunomarcação em cadelas, representada na coloração marrom, aumento de 200X, para colágeno I, sendo "A" região estroma da cérvice, "B" região muscular da cérvice, "C" região glandular do útero, "D" região muscular do útero e colágeno III, "E" região estroma da cérvice, "F" região muscular da cérvice, "G" região glandular do útero e " $\mathrm{H}$ " região muscular do útero. Imunoistoquímica, DAB, contra- coloração hematoxilina de Harris.

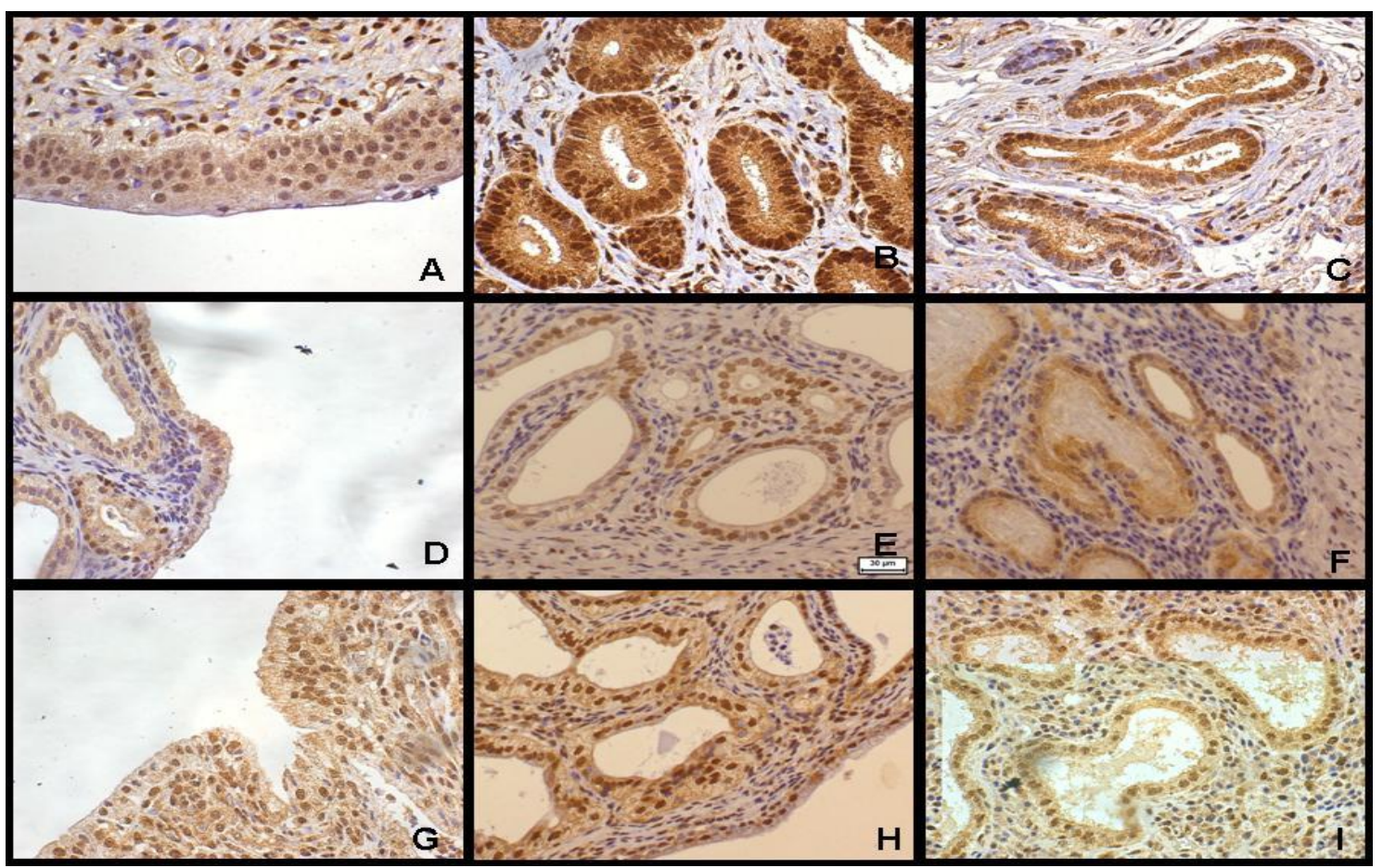

Figura 2. Detecção imunoistoquímica em cadelas, sendo considerados núcleos positivos aqueles corados em marrom, e negativos aqueles corados em azul. "A" receptores de progesterona no epitélio luminal da cérvice, aumento 400X, "B" receptores de progesterona no epitélio glandular e estroma da cérvice, "C" receptores de progesterona no epitélio glandular e estroma do útero, " $\mathrm{D}$ " receptores de estrógeno $\alpha$ no epitélio luminal da cérvice, "E" receptores de estrógeno $\alpha$ no epitélio glandular e estroma da cérvice, " $F$ " receptores de estrógeno $\alpha$ no epitélio glandular e estroma do útero, "G" receptores de estrógeno $\beta$ no epitélio luminal da cérvice, "H" receptores de estrógeno $\beta$ no epitélio glandular e estroma da cérvice, "I" receptores de estrógeno $\beta$ no epitélio glandular e estroma do útero, aumento 200X. Imunoistoquímica, $\mathrm{DAB}$, contracoloração hematoxilina de Harris. 
Estudos sobre receptores hormonais em útero de cadelas já foram realizados. Segundo Kunkitti et al. (2011), os REs e RP4 controlam a abertura e o fechamento cervical durante o ciclo estral; infelizmente o mecanismo envolvido, as mudanças e as associações bioquímicas que ocorrem nesse processo não são totalmente conhecidos.

A concentração dos RE $\alpha$ não apresentou diferença significativa entre os grupos estudados. A identificação e a quantificação de RE $\alpha$ também não apresentaram diferenças em nenhuma das regiões avaliadas no útero e na cérvice quando se comparam os grupos de piometra aberta e fechada.

A avaliação imunoistoquímica dos RE $\beta$ não apresentou diferença significativa quando se avaliaram o número de núcleos positivos e a intensidade de marcação entre os grupos piometra aberta e fechada, e nem entre as diferentes regiões do útero e da cérvice.

Aumento nas concentrações de estrógenos plasmáticos provoca um aumento no número dos REs e RP4s, já a diminuição nas concentrações desses receptores está relacionada com um aumento nas concentrações plasmáticas de progesterona (Galabova-Kovacs et al., 2003). Enquanto nos animais normais há uma diminuição nos REs sob a influência de progesterona ( $\mathrm{P} 4)$, esse mecanismo parece ser falho nas cadelas com HEC-piometra (de Cock et al., 1997).

No final do estágio secretório (diestro) e início do anestro, o endométrio das cadelas com HECpiometra tem uma quantidade significativamente maior de REs do que o observado no útero de fêmeas normais. Essa observação foi mais evidente nas glândulas basais do endométrio. Como resultado desse aumento dos REs, o endométrio permanece receptivo, mesmo com baixas concentrações de estrógeno (E2) circulante. Isto pode manter a proliferação das glândulas endometriais durante o estágio do ciclo estral, quando há uma forte influência de P4. Essa ação prolongada do E2 e da P4 pode explicar as modificações proliferativas císticas que caracterizam essa doença (Ververidis et al., 2004).
Quando se comparou a imunorreatividade dos $\mathrm{RE} \alpha$ entre as diferentes regiões do útero, observou-se que o epitélio glandular foi corado com intensidade mais forte do que o estroma, determinando concentração maior de RE $\alpha$ nessa região. Também na cérvice o epitélio glandular foi corado mais intensamente quando comparado com o estroma e o epitélio luminal. Levando em consideração que a concentração de receptores é diretamente proporcional à intensidade da marcação, a região com o maior número de RE $\alpha$ no útero e na cérvice é o epitélio glandular. Os resultados diferem dos observados por Dhaliwal et al. (1999) que encontraram escore muito baixo para RE e RP4 no epitélio glandular do útero.

Em relação à identificação dos RP4s, não houve diferença significativa entre os grupos de piometra aberta e fechada, entretanto houve diferença significativa na concentração de RP4s entre os grupos piometra aberta e fechada quando se consideraram as diversas regiões do útero. A imunorreatividade foi maior no epitélio glandular do útero, nas piometras fechadas. Em geral é aceito que os E2 induzem à proliferação das glândulas endometriais e que a P4 induz ao aumento da atividade secretora, sendo também responsável pelo início da fase secretória. Neste contexto, pode-se inferir que a produção de muco é maior nas piometras fechadas, uma vez que as concentrações de RP4s são maiores no epitélio glandular da condição fechada.

De acordo com Galabova-Kovacs et al. (2003), existe uma relação inversa entre os níveis de progesterona plasmática e as concentrações de RPs. Se forem considerados os resultados da presente pesquisa, os valores de progesterona foram maiores $(8,2 \mathrm{ng} / \mathrm{mL})$ nas piometras abertas e, portanto, seria esperada uma concentração menor de RPs, o que concorda com os autores acima mencionados e com a imunorreatividade observada nesta pesquisa.

Escores imunoistoquímicos de RP4s nuclear nas várias camadas do útero com HEC-piometra, durante o diestro, foram baixos de acordo com Dhaliwal et al. (1999). Concluiu-se, neste estudo, que há uma sensibilidade aumentada à ação de $\mathrm{P} 4$, pois altos níveis de $\mathrm{P} 4$ parecem ativar os $\mathrm{RP} 4 \mathrm{~s}$ no útero, provocando uma intensa diminuição na expressão e supressão do REs. 
Não foi observada diferença nas concentrações de RP4s entre a piometra aberta e a fechada na cérvice, entretanto a intensidade de marcação dos $\mathrm{RP} 4 \mathrm{~s}$ foi mais forte no estroma quando comparada com as intensidades mais fracas dos epitélios glandular e luminal. Portanto, existe um maior número de RP4s no estroma quando comparado às outras regiões da cérvice.

Os resultados deste experimento estão de acordo com os achados de Kunkitti et al. (2011), nos quais não foi verificada diferença significativa entre as cadelas com piometra aberta e piometra fechada utilizando como variáveis o número de núcleos positivos para receptores de estrógenos e progesteronas.

De Cock et al. (1997), de Bosschere et al. (2002a), de Bosschere et al. (2002b), de Bosschere et al. (2003) e Ververidis et al. (2004) estudaram os receptores de estrógenos e progesteronas no útero de cadelas normais e com HEC-piometra. Os resultados demonstraram diferenças importantes entre o número de REs e RP4s em cadelas com HEC e cadelas com piometra. As diferenças na expressão desses receptores sugerem fatores distintos na patogênese da HEC e da piometra. Esses autores, entretanto, não consideraram as diferenças dos receptores hormonais no mecanismo de abertura ou fechamento da cérvice.

A cérvice é a parte inferior do útero que apresenta poucas fibras musculares lisas e grande quantidade de tecido conjuntivo. A mucosa cervical é constituída por um epitélio prismático simples de células produtoras de muco e uma lâmina própria onde se encontram as glândulas cervicais. Na fase secretória do ciclo estral, os elevados níveis de progesterona influenciam essas glândulas a produzirem muco viscoso, que impede a passagem de microrganismos e de espermatozoides para dentro da cavidade uterina (Junqueira e Carneiro, 1999).

A invasão de células inflamatórias tem sido sugerida como uma possível causa de degradação de colágenos e relaxamento cervical; em mulheres, o grau de dilatação cervical está diretamente relacionado com a extensão do infiltrado neutrofílico, que pode posteriormente produzir enzimas colagenolíticas, como proteases e metaloproteinases. O aumento dessas enzimas pode degradar o colágeno recém- sintetizado e, assim, diminuir a proporção colágeno:musculatura lisa na cérvice, interferindo no grau de relaxamento cervical em cadelas com doenças uterinas (Kunkitti et al., 2011).

De acordo com Chatdarong et al. (2010), grande proporção de colágenos na cérvice de cadelas cíclicas é provavelmente associada com um aumento de estradiol durante o estro. Isto provoca diminuição na tensão, causando relaxamento cervical. Resultados semelhantes são observados em cadelas com piometra aberta, sugerindo que a abertura da cérvice é associada com o aumento na proporção de colágenos e fibras musculares.

Analisou-se, neste estudo, a proporção de colágenos I e III no útero e na cérvice de cadelas com piometra aberta e fechada, e não foi verificada diferença significativa entre as duas condições e nem entre os diversos tecidos investigados. Os resultados deste estudo demonstraram apenas que não houve diferença na proporção de colágenos entre a piometra aberta e a fechada.

As hipóteses inicialmente aventadas para explicar os mecanismos de abertura e fechamento cervical não se concretizaram, ou seja, a identificação e as concentrações de RE $\alpha$ e RE $\beta$, RP4 e colágenos I e III não estão implicadas nos mecanismos de relaxamento cervical. Avaliações das proporções de colágeno e fibras musculares são opções para o estudo da abertura cervical, conforme o considerado por Chatdarong et al. (2010), bem como o exame histológico comparativo da cérvice durante o trabalho de parto.

A piometra é uma enfermidade frequente em cadelas não castradas adultas ou idosas e, se não diagnosticada e tratada precocemente, pode levar o animal à morte. A despeito de décadas de pesquisa, alguns pontos na patogenia da piometra ainda não são completamente elucidados. Da mesma forma, os mecanismos envolvidos na abertura e no fechamento da cérvice não são conhecidos; as piometras abertas são menos tóxicas e mais fáceis de serem tratadas, e se os mecanismos de relaxamento cervical fossem esclarecidos, seria possível, no mínimo, estimular a abertura cervical e induzir a eliminação do conteúdo uterino. 


\section{CONCLUSÕES}

Com base nos objetivos propostos, conclui-se que os REa e RE $\beta$, colágenos I e III comportaram-se da mesma maneira na piometra aberta e na fechada, não estando envolvidos nos mecanismos de abertura e fechamento cervical, mas concentrações de receptores de progesterona foram mais elevadas nas piometras fechadas.

\section{REFERÊNCIAS}

ARORA, N.; SANDFORD, J.; BROWNING, G.F. et al. A model for cystic endometrial hyperplasia/pyometra complex in the bitch. Theriogenology, v.66, p.1530-1536, 2006.

BOOS, A.; MEYER, W.; SCHWARZ, R. et al. Immunohistochemical assesment of oestrogen receptor and progesterone receptor distribution in biopsy samples of the bovine endometrium collected throughout the oestrous cycle. Anim. Reprod. Sci., v.44, p.11-21, 1996.

BREEVELD-DWARKASING, V.N.A.; BOERBROUWER, M.; MÖSTL, E. et al. Immunohistochemical distribution of oestrogen and progesterone receptors and tissue concentrations of oestrogens in the cervix of non-pregnant cows. Reprod. Ferti. Dev., v.14, p.487-494, 2002.

CHATDARONG, K.; LINHARATTANARUKSA, P.; SIRIVAIDYAPONG, S.; SRISUWATAMASAKUL, $S$. The proportions of Smooth Muscle an Collagen in the Cervical Tissue of Bitches During Various Stages of the Estrous Cycle and Bitches Developing. In: Proceedings $9^{\text {th }}$ CHULALONGKORN UNIVERSITY VETERINARY SCIENCE THE ANIMAL COMPANY, 2010, v.1, p.129.

CHATDARONG, S.; $\quad$ KUNKITTI, P.; SRISUWATANASAGUL, S. P2 Distribution of Oestrogen Receptor and Progesterone Receptor and Leukocyte Infiltration in Canine Cervical Tissue. In: Proceedings $7^{\text {th }}$ CHULALONGKORN UNIVERSITY VETERINARY SCIENCE THE ANIMAL COMPANY, 7., 2008, v.1, p.58.

COGGAN, J.A.; OLIVEIRA, C.M.; FAUSTINO, M. et al. Microbiological study of intrauterine 440 secretion from bitches with pyometra and research of virulence factors of Escherichia 441 coli isolates. Arq. Inst. Biol., v.71, p.1-749, 2004.

DHALIWAL, G.K.; ENGLAND, G.C.W.; NOAKES, D.E. Oestrogen and progesterone receptors in the uterine wall of bitches with cystic endometrial hyperplasia/pyometra. Veterinary Record. v.145, p.455-7, 1999.
DE BOSSCHERE, H.; DUCATELLE, R.; TSHAMALA, M. Uterine Oestrogen and Progesterone Receptor Expression in Experimental Pyometra in the Bitch. J. Comp.Pathol. , v.128, p.99-106, 2003.

DE BOSSCHERE, H.; DUCATELLE, R.; VERMEIRSCH, H. et al. Estrogen and progesterone receptor expression in cystic endometrial hyperplasia and pyometra in the bitch. Anim. Reprod. Sci., v.70, p.251-259, 2002a

DE BOSSCHERE, H.; DUCATELLE, R.; TSHAMALA, M.; CORY, M. Changes in sex hormone receptors during administration of progesterone to prevent estrus in the bitch. Theriogenology, v.58, p.1209-1217, $2002 \mathrm{~b}$.

DE BOSSCHERE, H.; DUCATELLE, R.; VERMEIRSCH, H.; VAN DEN BROECK, W. Cystic endometrial hyperplasia-pyometra complex in the bitch: should the two entities be disconnected. Theriogenology, v.55, p.1509-1519, 2001.

DE COCK, H.; VERMEIRSCH, H.; DUCATELLEL, R.; DE SCHEPPER, J. Immunohistochemical analysis of estrogen receptors in cystic-endometritis-pyometra complex in the bitch. Theriogenology, v.48, p.10351047, 1997.

DOW, C. The cystic hyplerplasia-pyometra complex in the bitch. Vet. Rec., v.69, p.1409-1415, 1957.

DOW, C. The cystic endometrial hyplerplasiapyometra complex in the bitch. Vet. Rec., v.70, p.1102-1108, 1958.

FERREIRA, C.R.; LOPES, M.D. Complexo hiperplasia cística endometrial/piometra em cadelas revisão. Rev. Clin. Vet., n.25, p.36-44, 2000.

GALABOVA-KOVACS, G., WALTER, I., AURICH, C., AURICH, J.E. Steroid receptors in canine endometrial cells can be regulated by estrogen and progesterone under in vitro conditions. Theriogenology, v.61, p.963-976, 2004.

GOERICKE-PESCH, S.; SCHMIDT, B.; FAILING, $\mathrm{K}$; WEHREND, A. Changes in the histomorphology of the canine cervix though the oestrus cycle. Theriogenology, v.74, p.1075-1081, 2010.

HAGMAN, R.; LAGERSTEDT, A.S.; HEDHANMAR, A.; EGENVALL, A. A breedmatched case-control study of potential risk-factors of canine pyometra. Theriogenology, v.75, p.1251-1257, 2011.

JUNQUEIRA, L.C.; CARNEIRO, J. Aparelho Reprodutor Feminino. In: Histologia Básica. 9.ed.Rio de Janeiro: Guanabara-Koogan. p.367-88, 1999. 
KUNKITTI, P.; SRISUWATANASAGUL, S.; CHATDARONG, K. Distribution of estrogen receptor alpha and progesterone receptor, and leukocyte infiltration in the cervix of cyclic bitches and those with pyometra. Theriogenology, v.75, p.979-987, 2011.

MARTIN, I. Avaliação imunoistoquímica dos receptores de progesterona (isoformas $A$ e $B$ ), estrógenos $\alpha$ e $\beta$, hormônio luteinizante e das enzimas aromatase citocromo P450 e caspase-3 no corpo lúteo de vacas nelore (Bos taurus indicus) durante o ciclo estral. 2009. 117f. Tese (doutorado em Medicina Veterinária) Faculdade de Medicina Veterinária e Zootecnia, campus de Botucatu, Universidade Estadual Paulista.

MARTIN, I.; TORRES NETO, R.; OBA, E. et al. Immunohistochemical Detection of Receptors for Oestrogen and Progesterone in Endometrial Glands and Stroma during the Oestrous Cycle in Nelore (Bos taurus indicus) Cows. Reprod. Domest. Anim., v.43, p.415-421, 2008.

MARTINS, D.G. Complexo hiperplasia endometrial cística/piometra em cadelas: fisiopatogenia, características clínicas, laboratoriais e abordagem terapêutica. Jaboticabal, 2007. 54f. Dissertação (mestrado em cirurgia veterinária) Faculdade de Ciências Agrárias e Veterinárias, câmpus de Jaboticabal, Universidade Estadual Paulista.

OLIVEIRA, K.S. Cystic endometrial hyperplasia complex. Acta Sci. Vet., v.35, p.270-272, 2007.
OLIVEIRA, P.C; LOPES, M.D.; THOMÉ, H.E.; BALIEIRO, J.C.C. Avaliação citológica, histológica e hormonal de cadelas normais e com complexo hiperplasia endometrial cística/piometra. Vet. Zootec., v.15, p.150-159, 2008.

PRETZER, S.D. Clinical presentation of canine pyometra and mucometra: A review. Theriogenology, v.70, p.359-363, 2008.

RAGNI, R.A. Pyometra in a bitch following unusual sterilisation. J. Small Anim. Pract., v.46, p.39-40, 2005.

ROBINSON, R.S.; MANN, G.E.; LAMMING, G.E.; WATHES, D.C. Expression of oxytocin, oestrogen and progesterone receptor in uterine biopsy samples throughout the oestrous cycle and early pregnancy in cows. Reproduction, v.122, p.965-979, 2001.

SMITH, F.O. Canine pyometra. Theriogenology, v.66, p.610-612, 2006.

VERVERIDIS, H.N.; BOSCOSA, C.M.; STEFANAKISB, A. et al. Serum estradiol-17b, progesterone and espective uterine cytosol receptor concentrations in bitches with spontaneous pyometra Theriogenology, v.62, p.614-633, 2004.

WEISS, R.R.; CALOMENO, M.A.; SOUSA, R.S. et al Avaliação histopatológica, hormonal e bacteriológica da piometra na cadela. Arch. Vet. Sci., v.9, p.81-87, 2004. 